\title{
KITCHEN AND ELECTRONIC MODEL FOR PREVENTION OF FIRES CAUSED BY COOKING GAS LEAKAGE IN RESIDENTIAL BUILDINGS
}

\author{
${ }^{1}$ Okeoma, G, and ${ }^{2}$ Ezetoha F. C \\ ${ }^{1}$ Department of Building Technology, Federal Polytechnic, Oko, Anambra State \\ ${ }^{2}$ Department of Computer Engineering Technology, Federal Polytechnic, Oko, Anambra \\ State
}

\begin{abstract}
Cooking gas or liquefied petroleum gas usage for cooking has increased in recent times. Though gas stoves offer enhanced initial heating speed, better temperature control, visual monitoring of flames, compatibility with an array of cookware, and ability to use diverse cooking methods, fire outbreaks in residential buildings have increased because of its usage. The fire incidences have mainly occurred as a result of undetected gas leakage due to lack of gas leakage detector and supported by poorly designed kitchens and lack of awareness on safety measures on gas stove usage.This paper presents kitchen and electronic model for prevention of fires caused by cooking gas leakage in residential buildings. The aim of thework was to design a model that prevents fires caused by cooking gas leakage in residential buildings. The model consists of isolated kitchen model and electronic system. The electronic model; an AT9C51 microcontroller-based system that operates 24 hours a day and can detect gas leakage in kitchen, informs user and occupants about the condition and what to do to avert fire.The kitchen model is an isolated type constructed with fire resistant materials, having enough space and ventilation, fire extinguisher and plates written warning and safety measures installed. The model prevents fires caused by cooking gas leakage in kitchen and its spread in residential building. It was recommended that this model be adopted in order to prevent fires caused by cooking gas leakage in residential buildings.
\end{abstract}

Keywords: Isolated kitchen, electronic system, cooking gas leakage, fires, residential buildings.

\section{INTRODUCTION}

Fire outbreaks in residential buildings have increased since use of cooking gas or liquefied petroleum gas (LPG)for cooking increased in recent years especially in developing countries like Nigeria. The reason for the increased usage of LPG is scarcity of kerosene and firewood and irregular supply of electricity (Ohajianya, Abumere, Owate, \& Osarolube, 2014) used for operating electric stoves/cookers. In addition, gas stoves offer enhanced initial heating speed, better temperature control, visual monitoring of flames, compatibility with an array of cookware, and ability to use diverse cooking methods.

Series of fire incidences have occurred in residential buildings in Nigeria as a result of lack of awareness on safety measures taken while using cooking gas system. Majority of the fire incidences are as a result of not watching for gas leakage in kitchens before igniting or switching OFF and ON appliances (Eno-Abasi and Akutu, 2017) due to lack of gas leakage detector in kitchens or lack of knowledge of hissing sound and smell of gas indicating leak. The effects of the fire incidences include injuries and loss of properties and lives. Gas leakage of cooking gas system may be caused by faulty or worn out regulator, worn out or expired rubber hose, slacked hose clip or cylinders having cracks, dents or rust (Utuk, 2017), expired 
cylinder or poor handling such as not storing an LPG stove in an upright position. Moreover, it is expected that up to 13.8 million households (more than 40 million people) in Nigeria will embrace the usage of Liquefied Petroleum Gas (LPG) for their cooking within the next five years (Onyekwelu, 2020) and this Requires roper awareness on usage and prevention of fires caused by its leakage.

Earlier electronic systems/devices developed for prevention of fires caused by cooking gas leakage detect leakage and inform the kitchen cook and other occupantsto enable action to be taken while few of the systems developed later detect gas leakage and automatically shuts off supply through the gas valve and informs cook and other occupants(Apeh, Erameh, and Iruansi, 2016). Theseelectronic systems depend on alternating current (a.c) source or public power supply and they do not operate when there is power outage. On the other hand, the systems might malfunction as a result of faulty or damaged component used in their manufacture and any gas leakage in the kitchen will be undetected and may cause fire outbreak. However, the systems do not stop leakages from the cylinder (gas container). Additionally, fire can break out as result of accident such as falling of cylinder; in this case, leakage might not be detection before ignition of fire.

Furthermore, majority of the modern kitchens are integrated in the main buildings and most of them do not have enough ventilation to enable circulation of air so that the concentration of leaked gas will not be high to support ignition of fire. In addition, materials such as ceilings, doors and windows used in constructing these kitchens and the kitchen furniture are not fire resistant and fire can spread through them. On the other hand, the use of electronic system to shutdown power or gas supply remotely when there is gas leakage or when fire starts in kitchens (Eurofireprotection, 2015) in order to avert fire or its spread in building will be in vein if leakage is from the cylinder since gas supply cannot be shutdown and kitchens not isolated from the main building. A model that can detect gas leakage, informs kitchen user and occupants about the condition, directs them on actions to be taken, provides safety tips on gas stove usage and prevents spread of fires if ignited is therefore necessary for effective prevention of fires caused by cooking gas leakage in residential buildings

The aim of this work is to design kitchen and electronic model for prevention of fires caused by cooking gas leakage in residential buildings.

\section{LITERATURE REVIEW}

It's mostly negligent and careless handling of gas stove that leads to explosion/fires caused by gas leakage. The cooking gas or LPG is a petroleum product containing a flammable mixture of hydrocarbon gases like butane and propane (Ashish, Ratnesh, Rajeev \& Rahul, 2013). It also contains propylene, butylene, isobutane, and other low molecular weight hydrocarbons that are refined from petroleum which is heavier than air. The propane and butane gases have been compressed so much that it turns to liquid and occupies about 274 times less space than normal. LPGmay be referred to as bottled gas, compressed petroleum gas, liquefied hydrocarbon gas, or Propane-butane-(propylene) and Pyrofax.The proportion of propane to butane varies in amount depending on the intended purpose-for small portable canisters, barbecue stove or large household tanks. Normally, LPG is odourless but a small amount of pungent gas, ethanethiol, is added to it to help perceive gas leaks.

\section{Cooking Gas Leakage}

Gas leakage of cooking gas system is caused by many factors linked to human errors and malfunctioning and damage of gas stove components. According to Utuk (2017), cooking gas leakage can be caused by:

- Regulator that is worn out or faulty.

- Rubberhose that is either worn out or expired. 
- Slacked hose clips.

- Gas cylinder that have cracks, dents or rust.

- Storing/keeping cylinder in poor ventilated place with high temperature.

- Keeping cylinder horizontally while transporting it instead of sitting the cylinder upright and with the valve facing upwards.

- Fallen cylinder.Cylinder which falls to the ground may have its valve damaged and thereby cause rapid release of high pressured gas to the surrounding.

According to Eno-Abasi \& Akutu (2017), gas cylinders may corrode with age and if improperly handled or wrongly exposed, results in wear and tear and this can cause leakage. Gas cylinders may expire and when expired, it can leak gas (Ajaja, 2019).Expiring date is found around the top, pillar, or neck of the cylinder(Ubong, 2018), where the dates and other details are usually stamped (i.e. on the inner part of one of the metal strips serving as the handle of the cylinder). According to Eno-Abasi et al. (2017), most cylinders in Nigeria only show date of testing, leaving one with visual determination as to when the cylinder is too weak to leak gas.

Lack of maintenance can also cause cylinder to leak gas. According to Ajaja (2019), cylinders have expiry dates and a lifespan of about 15 years during which they are to be maintained every five years. Maintenance or re-qualification is done by company that has the facility to re-qualify it and is done three times every five years and most users of gas cylinder are unaware of this.

\section{Prevention of Fires Caused by Cooking Gas}

According to Ozonetech (2018), there are three conditions that must be met in order for a fire to start; heat, oxygen (air) and fuel (Ozonetech, 2018). All of these factors are present in varying degrees in a kitchen. In case of fire caused by LPG leakage, leaked gas mixes with air, forming a combustible mixture; a spark or a source of ignition (heat or flames) ignites the combustible LPG-air mixture and this leads to an explosion (SUPERGAS, 2018). Prevention of fires caused by cooking gasinvolvesdetection of gas leakage, stopping gas flow or reducing concentration in air and carefully fixing the problem that caused leakage.

Cooking gas leakage can be detected manually or automatically. Manual methods involve listening to hissing soundor perceiving of smell of gas (Architecturelab, 2018; Rapportnaija, 2017).

Automatic detection of cooking gas leakage is done by electronic devices/systems such as LPG detector. One type of detector detects gas leakage and sends SMS to the householder (Soundarya, Anchitaalagammai, Deepa \& Sheela, 2014; Zhijie, Wang \&Luojun, 2011).This type does not make provision for halting further gas leakage by shutting off gas supply. Shutting off gas supply is done manually. Another type of detector detects gas leakage, automatically turns off gas supply and sounds an Alarm (Apeh et al., 2016). Yet, another type of detector detects gas leakage, alerts (Beep), turns off main power and gas supplies and send an SMS to kitchen cook or house owner via GSM module (Ashish et al, 2013). These systems do not stop gas leaks from the body of cylinder and depend on alternating current (a.c) source.

Tracing of problem or point of leakage involves checking for gas leaks through the use of liquid soap solution applied on cylinder joints (Utuk, 2017), hose and its connections. The presence of bubbles from the soap indicates a gas leakage. According to Architecturelab (2018), an alternative method involves observing point where hissing sound of gas is heard.

Fixing of the problem that caused leakage may involves replacement of faulty and worn out regulator, or worn out or expired rubber hose for stoves with hose, tightening loose hose clip, or replacement of cylinders that have expired or have dent, rust and crack 
These electronicsystems (detectors) do not stop leakages from the cylinder. The systems depend on alternating current (a.c) source or public power supply and they do not operate when there is power outage and so leakage during this period will be undetected and fire can be ignited unknowingly. On the other hand, the systems might malfunction as a result of faulty or damaged component used in their manufacture and in this case fire can break out in the building. Moreover, the systems installed with valves for shutting off gas supply requires disconnection before taking the cylinder for refilling and reconnection after refilling. Regular disconnectionand reconnection of valves may cause gas leakage. Additionally, fire can break out in kitchens constructed and equipped with non-fire resistant materials and not isolated from the main building as a result of gas leakage caused by accident such as falling of cylinder, which may be undetected before fire is ignited. On the other hand, the electronic systems do not direct cook or occupants alerted of gas leakage on the safest action to be taken in order to avert fire outbreak.

The proposed model is an isolated kitchen and electronic model for prevention of fires caused by cooking gas leakage in kitchen and its spread in residential building.

\section{THE MODEL}

The proposed model comprises of an isolated kitchen constructed with fire resistant materials and having enough space and ventilation, warning sign, safety tips and fire extinguisher and an electronic system that operates 24 hours a day and can detect gas leakage, informs kitchen user and occupants about the condition, directs them on actions to be taken.

\section{Kitchen model}

The kitchen is isolated from the main building and constructed and equipped with fire resistant materials, has enough space to accommodate cabinet and appliances, has adequate ventilation and fire safety facilities based on Singapore Civil Defense Force 2015 fire safety requirements for LPG cylinder installations (SCDF, 2015).Top-down design approach was adopted for designing of the isolated kitchen. This approach was used because it allows decomposition of the structure/kitchen into smaller compartments in order to comprehend its composition. .

The isolated kitchen compartments include kitchen service/circulation area, walkway, chimney and cabinet.The kitchen also has safety facilities. The front and the right views of the kitchen are shown in figures 1 aand $1 \mathrm{~b}$ respectively.

Kitchen Service/Circulation Area: The kitchen has length of $6.299 \mathrm{~m}$ and width of $5.000 \mathrm{~m}$. The space is sufficient to accommodate a standard kitchen cabinet and appliances and yet have free space.

The door is of standard metallic type while the windows are made of transparent glass and aluminum frame. The door is positioned at the connection of the walkway and the kitchen. The kitchen has 5 windows. 3 of which are positioned in three sides of the kitchen while the remaining 2 are positioned on the same frontal wall with the door. The window arrangement and chimney position make it possible for this design to have adequate ventilation.

The roof is ofconcrete type and no ceiling is integrated in the design. The roof which is leanto is of standard storey height, the upper end measuring $4.000 \mathrm{~m}$ and lower end measuring $3.300 \mathrm{~m}$ thereby providing sufficient fall/gradient for effective water fall or rain water flow. The concrete roof was chosen for this design because it is fire resistant and therefore prevents spread of fire to the main building.

Chimney. The chimney or extractor hood is of reinforced concrete and is positioned at the end of the kitchen opposite to the door and extends above the roof top. The chimney is 
ofstraight line type and has dimensions of $2.500 \mathrm{~m} \times 2.399 \mathrm{~m}$, adequate vent (4 vents) and large suction area. The size of the chimney used is ideal as kitchen chimney size depends on the size of the stove, hob and kitchen size. It is required that the kitchen chimney size should be slightly greater than the stove or hob size so that it covers entire stove or hob and absorbs smoke and other gasses effectively (Shareef, 2018). Use of stoves with up to 5 burners under the chimney is supported in this design. Chimney is integrated in this design to vent fumes released when fire comes into contact with the cookware outdoors immediately. The chimney and windows positioned in strategic places, makes it possible to ventilate the fumes and smoke. (Architecturelab, 2018).

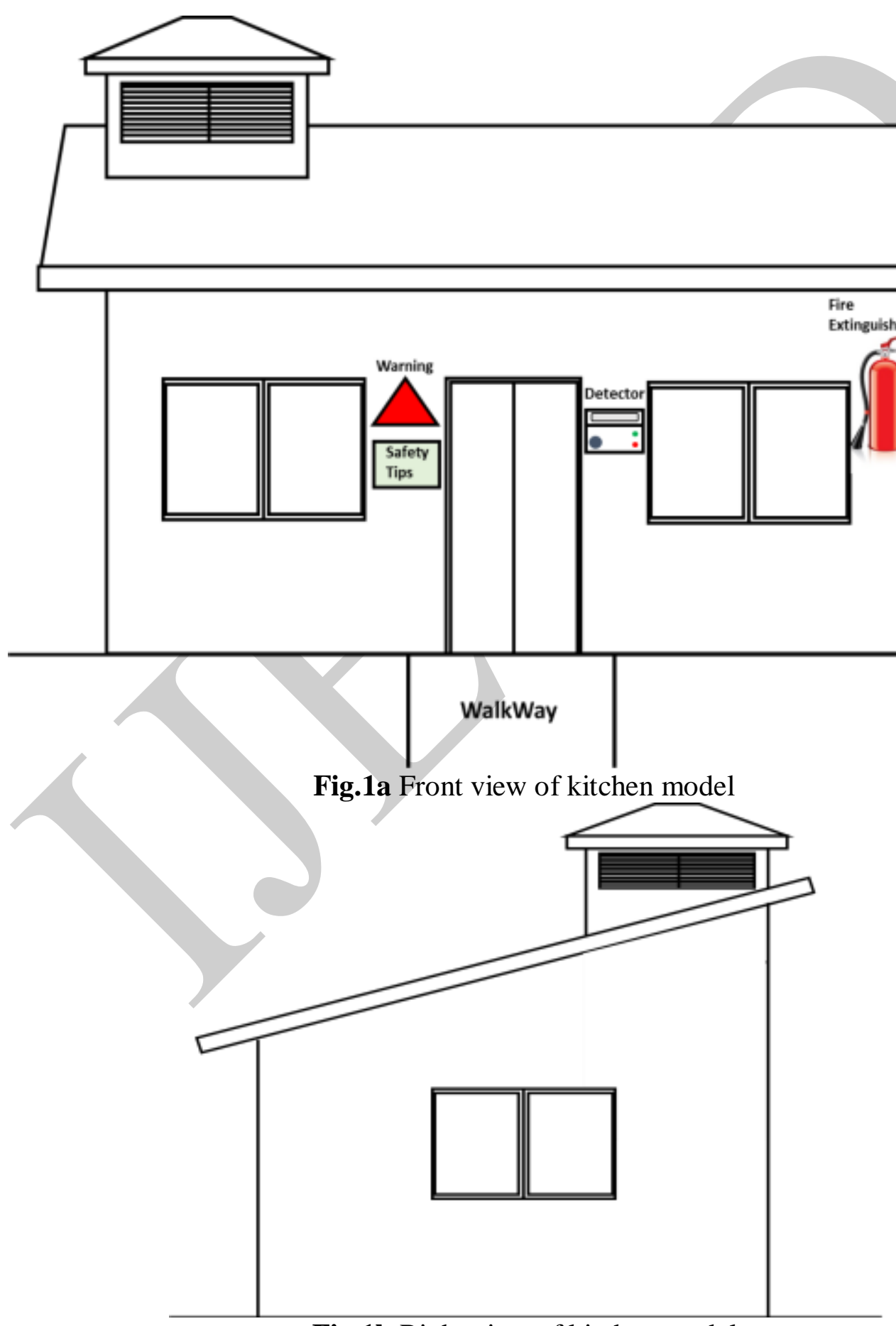

Fig.1b Right view of kitchen model 
Cabinet. The kitchen cabinet is of metallic material. The metallic material was chosen because it is a fire resistant material and therefore, prevents spread of fire.

Walkway. The walkway is the connection between the main building and the kitchen. It is $1.5 \mathrm{~m}$ wide and $4 \mathrm{~m}$ long and its floor is made of concrete. Thewalkway stands as a barrier to fire as fire cannot spread through it since it is constructed with fire resistant materials and separated from the kitchen and main building by enough distance.

Safety Facilities: The safety facilitiesintegrated in the design aremetallic plates written warning sign/notice(highly flammable) and safety tips/measures on how to use gas stove, gas leak detector and fire extinguisher. The safety facilitiesare fixed on the front wall as shown in figure 1a. The positions of the safety tips, warning and detector are ideal as they must be seen and read before anyone enters the kitchen. The position of the fire extinguisher is also ideal as it is outside and easily accessible. The safety tips include instruction for observation of the cooking gas system for gas leakage and other safe practices in kitchen.

\section{Electronic model}

The electronic model is a microcontroller-based system. It consists of power supply, LPG sensing, control, status indicating, alarm, SMS and displayunits as shown in block diagram of figure 2 .

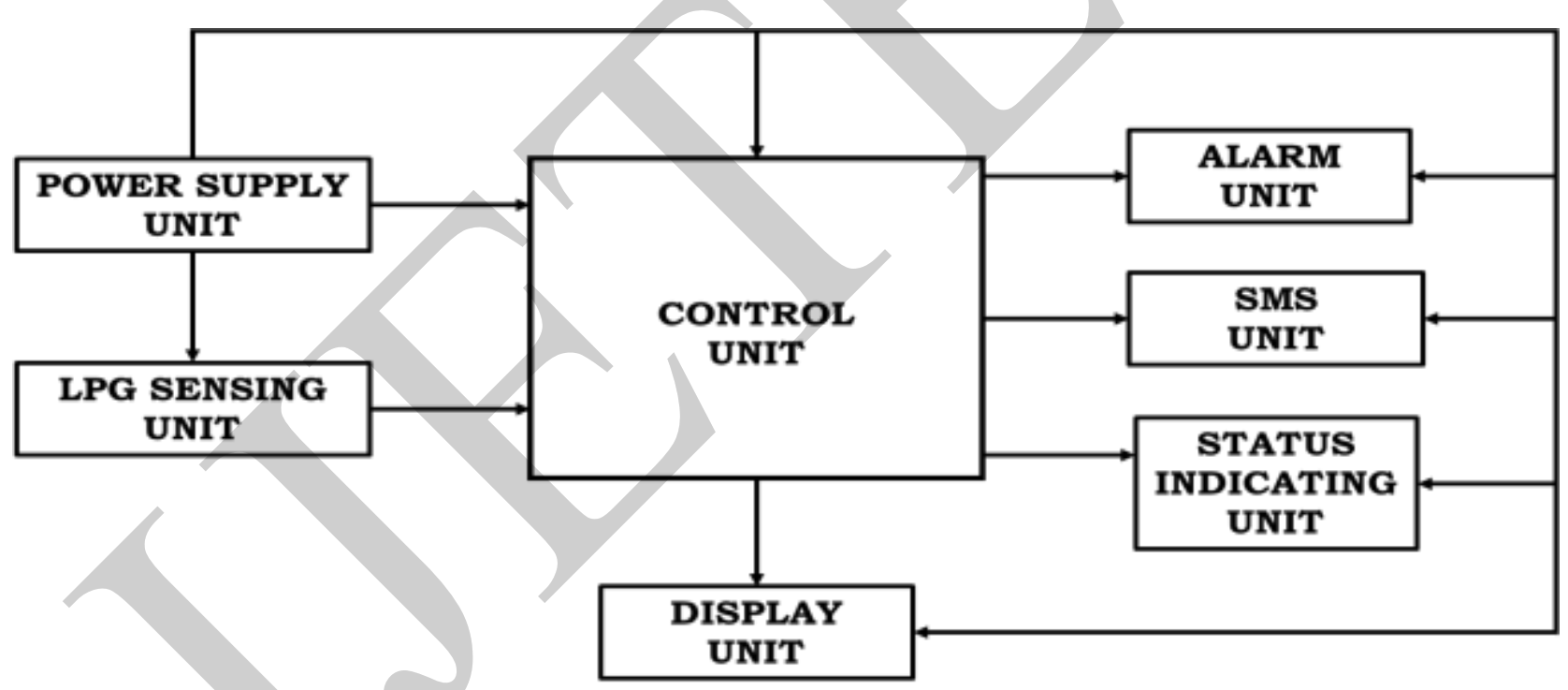

Fig. 2 Block diagram of the electronic model

Power supply unit. The power supply unit provides a regulated $5 \mathrm{v}$ direct current $(\mathrm{dc})$ needed for powering the system. The input voltage to this unit is supplied by 230v alternating current (a.c) mains or $9 \mathrm{v}$ battery. The battery supplies power when there is no ac power while the $230 \mathrm{v}$ a.c mains supplies power when it is available thereby providing regular power supply. An automatic change over switch (relay circuit) is used in this design (figure 3) to automatically supply electric power to the system.

LPG sensing unit. MQ6 gas sensorwas used as sensing unit. MQ6 senses gas leakage in the kitchen and sends signal to the microcontroller which in turn takes action on how to prevent fire. MQ6 was chosen because it is simple-to-use, has a high sensitivity and fast response timeand suitable for sensing LPG (composed of mostly propane and butane) concentrations in 
the air ranging from 200 to $10000 \mathrm{ppm}$. The sensor's output is an analog resistance. The sensor uses $5 \mathrm{v}$ supply and connected to other subunits as shown in figure 3.

Control unit. The 89C51 microcontroller serves as control unit and was used for coordinating the activities of the entire system. Binary output from the MQ6 sensor is interfaced with ports of the microcontroller. The microcontroller takes decision depending on the signal it receives from MQ6 sensor. The 89C51 microcontroller was used because it is dedicated to one task and run one specific program.

Indicating unit. The indicating unit consists of two red LEDs and two greenLEDs. LEDs where chosen because of their low power consumption and visibility. The greenLEDs indicate that there is no gas leakage while the two red LEDs indicate that there is gas leakage. One red and one green LED is fixed on the case while the remaining red and green LEDs are fixed at a strategic position in the main building.

Alarm unit.The alarm unit consists of two 5v buzzers. The buzzers produce loud sound and flashes to warn the residents when gas leakage is detected. $5 \mathrm{v}$ buzzer were chosen because of its low input voltage range of $3 \mathrm{v}$ to $8 \mathrm{v}$ and $40 \mathrm{~mA}$ current requirements, $80 \mathrm{~dB}$ at $20 \mathrm{~cm}$ sound output and it is easy to connect to systems

SMS unit.The SMS unit consists of an SIM900A GSM module and MAX232 IC. The GSM module is primarily used for wireless communication between the gas detector system and a mobile phone with the target (kitchen user or house owner) subscriber identity module (SIM) card while MAX232 IC is used for serial communication between the module and a DTE (data terminal equipment). The GSM module was chosen for this design because it has an onboard voltage level converter and can send SMS in real time when this network service.

Display unit.The display unit consists of a 20x4 liquid-crystal display (LCD). The display unit displays instructions on what to do when gas leakage is detected. The

20x4 LCD was chosen because it has built-in controller (S6A0069 or equivalent), requires $+5 \mathrm{~V}$ power supply, can display 20 characters in each of the 4 rows (a total of 80 characters can be displayed at any instance of time) and can be easily connected and controlled by microcontroller such as 8051 .

Circuit diagram of electronic model.Circuit diagram of electronic model for prevention of fires caused by cooking gas in residential building is shown in figure 3 .

The electronic model or detector performs its function based on program written for it. It indicates no gas leakage through green LEDs on its case and on strategic position inside the house. If the system detects gas leakage, it immediately activate the buzzers/alarmsto produce loud sound and flashes to warn the residents,switches ON the red LEDs and sends message (gas leakage detected) to cook/house owner. The LCD then displays instructions-don't panic, don't operate switch,turn off regulatorand thenopen windows and doors. Opening of windows and doorshelps to disperse the concentrated gas.The LCD then displays instruction-trace leakage and then stop leakage when gas leak is still detected. 


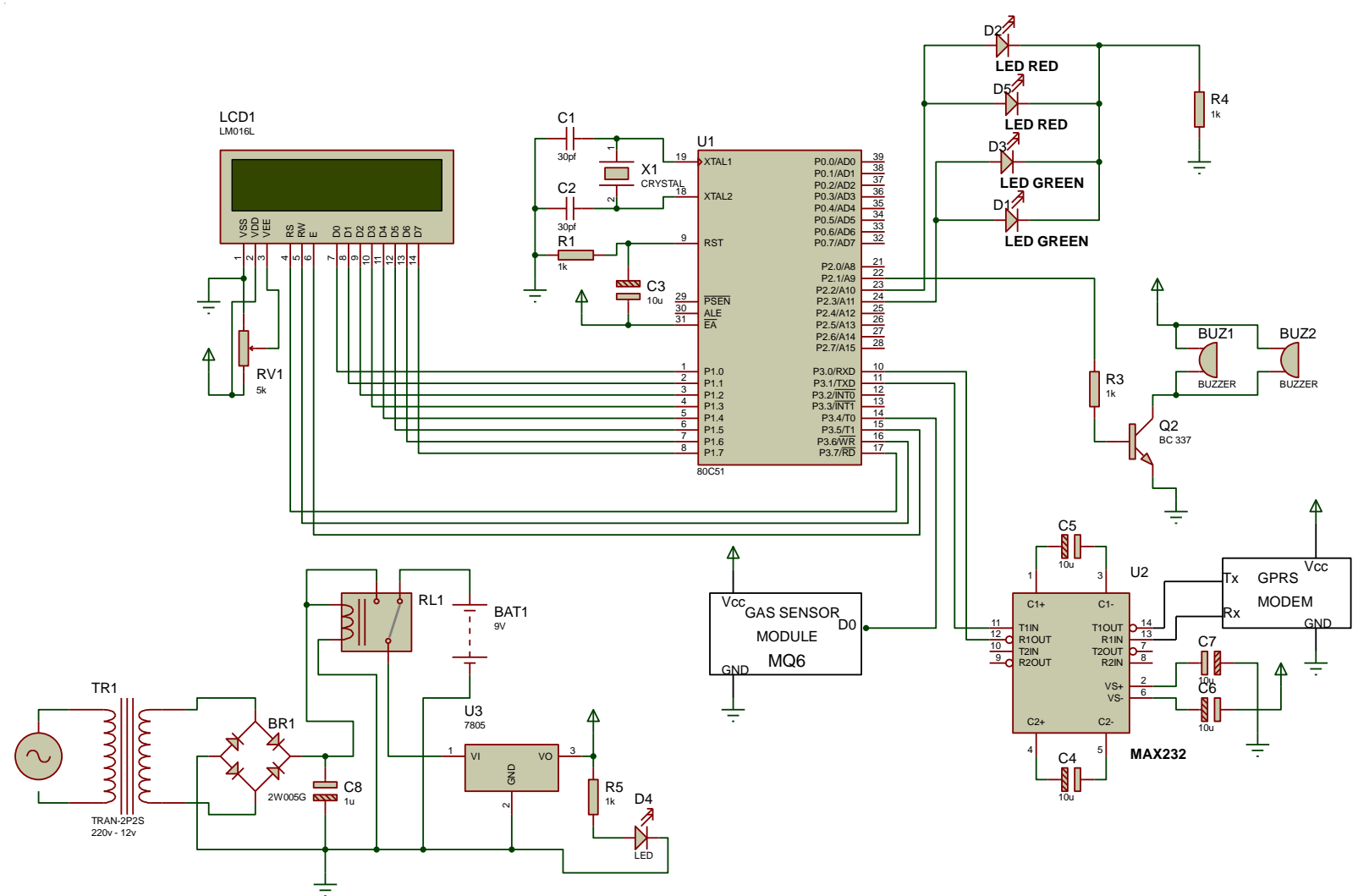

Fig. 3 Circuit diagram of electronic model for prevention of fires caused by cooking gas in residential building

\section{Conclusion}

The model consists of isolated kitchen model and electronic system. The electronic model, an AT9C51 microcontroller-based system that operates 24 hours a day and can detect gas leakage in kitchen, informs user and occupants about the condition and what to do to avert fire. The kitchen model is an isolated type constructed with fire resistant materials, having enough space and ventilation, fire extinguisher and plates written warning and safety measures installed. The model prevents fires caused by cooking gas leakage in kitchen and its spread in residential building.

Themodel is a universal type; it can be adopted for use in both rural and urban areas since it uses both a.c and d.c power sources.

It is necessary to adopt model in order to prevent fires caused by cooking gas leakage in residential buildings.

\section{REFERENCES}

1. Ajaja, T. (2019). Dangerous cylinders: needless deaths in Nigeria's poorly regulated cooking gas sector.Punch Newspaper. Retrieved fromhttps://punchng.com/dangerouscylinders-needless-deaths-in-nigerias-poorly-regulated-cooking-gas-sector/

2. Apeh, S. T, Erameh, K. \& Iruansi, U. (2016). Design and development of kitchen gas leakage detection and automatic gas shut off system. Journal of Emerging Trends in Engineering and Applied Sciences (JETEAS), 5(3), 222-228

3. Architecturelab. (2018). 11 Gas stove safety tips everyone should know. Retrieved from https://www.architecturelab.net/11-gas-stove-safety-tips-everyone-should-know/ 
4. Ashish S., Ratnesh P., Rajeev K \& Rahul, V. (2013). GSM based gas leakage detection system. International journal of technical research and applications 1(2), 42-45

5. Eno-Abasi, S \& Akutu, G. (2017, November 19). Stemming cooking gas-related accidents/deaths. Retrieved from https://guardian.ng/features/stemming-cooking-gasrelated-accidentsdeaths/

6. Eurofireprotection. (2015). 10 Ways to prevent commercial kitchen Fires, retrieved from http://www.eurofireprotection.com/blog/10-ways-to-prevent-commercial-kitchen-fires/

7. Ohajianya1, A. C., Abumere, O. E,. Owate, I. O \& Osarolube, E. (2014). Erratic power supply in Nigeria: causes and solutions, International Journal of Engineering Science Invention, 3(7), 51-55.

8. Onyekwelu, S. (2020). Nigeria's cooking gas market yet to capture over $80 \mathrm{~m}$ rural dwellers. Retrieved from https://businessday.ng/energy/article/nigerias-cooking-gasmarket-yet-to-capture-over-80m-rural-dwellers/

9. Ozonetech. (2018). Common causes of kitchen fires. Retrieved from https://www.ozonetech.com/ozone-kitchen-exhaust/common-causes-of-kitchen-fires/

10. Rapportnaija. (2017). How to prevent a gas explosion: 6 essential tips that can save your life. Retrieved from https://www.rapportnaija.com/2017/06/how-to-prevent-gasexplosion-in-home.html

11. SCDF. (2015). Fire safety requirements for liquefied petroleum gas (LPG) cylinder installations. Singapore civil defense force (SCDF). Retrieved from https://www.scdf.gov.sg/firecode/table-of-content/chapter-10-requirements-for-specialinstallations/clause-10.1

12. Shareef, U. (2018). How to choose the right kitchen chimney size. Retrieved from, http://www. zelect.in/kitchen-chimney/kitchen-chimney-size

13. Soundarya, T., Anchitaalagammai, J. V., Deepa, P. G \& Sheela, K. S. (2014). Efficient energy (LPG) gas leakage detection and prevention system for home safety. Artificial intelligence systems and machine learning. Vol 6, No 1.

14. SUPERGAS. (2018). LPG cylinder explosion: reasons and precautions. Retrieved from https://www.supergas.com/media/blog/lpg-cylinder-explosion-reasons-and-precautions

15. Ubong, E. (2018). How to check LPG cylinder expiry date.Health safety and environmental watch (HSE Watch). Retrieved from https://hsewatch.com/how-to-checklpg-cylinder-expiry-date

16. Utuk, M. (2017). 8 Valuable cooking gas safety tips that can protect your life, family and neighbours. Retrieved from https://infoguidenigeria.com/cooking-gas-safety-tips/

17. Zhijie, T.,Wang, S \& Luojun, A. (2001). Remote alarm monitor system based on GSM and ARM. Advances in Control Engineering and Information Science. Elsevier Ltd. Procedia Engineering, 15, 65 -69. 